Archived version from NCDOCKS Institutional Repository http://libres.uncg.edu/ir/asu/

Cherry, T. L. \& Cotton, S. (2011). Sleeping with the enemy: The economic cost of internal environmental conflicts. Economic Inquiry, 49(2), 530-539. Publisher's version available from

http://www.wiley.com/WileyCDA/ (ISSN: 0095-2583) DOI: 10.1111/j.1465-7295.2010.00329.x

\title{
SLEEPING WITH THE ENEMY: THE ECONOMIC COST OF INTERNAL ENVIRONMENTAL CONFLICTS
}

TODD L. CHERRY and STEPHEN J. COTTON

\begin{abstract}
This paper extends the literature on collective rent-seeking by introducing the possibility that a competing group may be a subset of another. We develop a model that incorporates the potential for some individuals to be party of both sides of a conflict, which creates interdependence of payoffs. Results indicate that strategic individual behavior, and the resulting rent dissipation, is affected by the relative size of the groups. We conduct an experimental test of the model and find that observed laboratory behavior corresponds well with the game-theoretic comparative-static predictions.
\end{abstract}




\section{INTRODUCTION}

In 1996, a conflict emerged between Watauga County, NC, and its county seat, the Town of Boone, over the cost of an environmental cleanup. The problem arose when inspectors found the county landfill was leaking cancer-causing pollutants into nearby wells, and mandated its closure at an expected cost of $\$ 2.6$ million. Though owned by Watauga County at the time contaminants were discovered, Boone had operated the landfill for over 30 years before the county assumed control in 1985. Furthermore, the town remained a heavy user of the landfill after control was given to the county. Breakdown of negotiations led to a federal lawsuit under the Comprehensive Environmental Response, Compensation and Liability Act-i.e., Superfund. The irony of the conflict is that town residents, who comprise about $35 \%$ of the county's 42,000 residents, supported both sides of the contest with their tax revenue while anticipating they would bear some of the financial responsibility regardless of the outcome.

The theory of rent-seeking provides insights on the economic consequences of individuals or groups competing with one another to win a rent. Pioneered by Tullock $(1967,1980)$, the theory suggests that efforts to secure a rent, such as lobbying, litigation, and investigations, tend to be wasteful because they are redistributive rather than productive.2 Katz, Nitzan, and Rosenberg (1990) and Ursprung (1990) extended the theory to explore collective rent-seeking, i.e., contests between groups of individuals, in which individuals decide the extent of participation in the groups' efforts. Subsequent work on collective rent-seeking has extended the investigation in various directions, such as characteristics of group sharing rules (Lee 1993; Nitzan 1991), intragroup mobility (Baik and Lee 1997, 2001), the rent being a pure public good (Baik 1993; Riaz et al. 1995), or some mixture of a public-private good (Esteban and Ray 2001). Previous research, however, has focused on variants of contests involving two independent groups and has yet to consider contests between interdependent groups (i.e., a group and a subset of itself). Such internal conflicts are not uncommon. Examples of internal conflicts include a \$268+ million conflict between California and a group of 14 California cities over the responsibility of contamination at the Monterey Park Landfill; a recent legal battle between California and San Francisco over same-sex marriage laws; and more generally, a college competing with one of its departments to secure resources from the university administration.

The purpose of this paper is to extend the collective rent-seeking literature by introducing the possibility that competing groups may be interdependent. We develop a model of conflict between nonautonomous groups and find that strategic individual behavior, and the resulting rent dissipation, is affected by the relative size of the groups. We visit the lab to test the model and find that observed laboratory behavior corresponds well with the comparative statics predicted by theory. While previous experimental studies have explored contests between individuals, we provide the first laboratory investigation of contests between groups, allowing us to incorporate the effect of intra-group dynamics on behavior. We find greater levels of cooperation than theory predicts-a result consistent with the experimental evidence on social dilemmas. 


\section{THEORETICAL MODEL}

Following the collective rent-seeking literature (e.g., Baik 1994; Lee 1995; Nitzan 1991), consider a conflict between two groups, in which the groups compete for a fixed prize, which is a pure private good that can be divided among group members. Assume for simplicity that the entire prize goes to the victorious group and will be subject to a sharing rule wherein each member of the victorious group receives an equal share of the prize. Knowing this, group members voluntarily and individually decide the level of effort spent in the conflict. We extend this now by considering the conflict is between a group and a subset of that group.

For conceptual ease, define the competing group and subset of that group respectively as county and town. Those county members that are not part of the town are defined as rural. Let the population of the county be $m$ and the population of the town be $n$, and necessarily $m \geq n$, with no inter-group mobility. Therefore, the rural population is $(m-n)$ and the relative size of the town to county is $(\varphi=n / m)$. A conflict, between county and town, erupts over an exogenous prize, $g$, (e.g., the avoided cost of environmental cleanup). Individuals may exert costly effort to influence the outcome of the conflict. Assuming individuals exert effort for one side of the conflict, we stratify individual effort by town and rural membership. Let individual effort of each town member be $x t i$ where $i$ $=\{1, \ldots, n\}$ and that of each rural member be $x r j$ where $j=\{1, \ldots, m-n\}$. Individuals are identical, and thus we refer to the individual efforts of representative town and rural members as $x t$ and $x r$, respectively. Total group effort, town and rural, is the sum of individual members' effort and denoted as $X t$ for town and $X r$ for rural.

Group payoffs are dictated by one of two possible outcomes of the conflict-county wins or town wins. When either group wins, it avoids some or all of the cleanup costs and the other group pays the remaining bill with the intragroup sharing rule exogenously set at sharing costs equally among members of the liable group. Again, stratifying by town and nontown (rural) membership, the town pays $g$ if the county wins, while the rural group pays 0 . If the town wins, the town and rural groups pay in proportion to their sizes-the town paying $n(\mathrm{~g} / \mathrm{m})$ and the rural group paying $(m-n)(\mathrm{g} / \mathrm{m})$. Individually, if the county wins, town members pay $g / n$ and rural members pay 0 . If the town wins, all members of the county (town and rural) pay $g / m$. Let $p t(X t, X r)$ represent the probability of success for the town, with $\operatorname{pr}(X t, X r)$ representing that for the rural group. Following the contest literature, assume a logit functional form for the group probability functions (see Dixit 1987; Tullock 1980). The logit contest-success function captures the dynamic that relative effort influences the likelihood of winning. The probabilities for success are:

$$
\begin{aligned}
& p^{t}\left(X^{t}, X^{r}\right)=\left(\frac{X^{t}}{X^{t}+X^{r}}\right)=\left(\frac{n x^{t}}{n x^{t}+(m-n) x^{r}}\right) \\
& p^{r}\left(X^{t}, X^{r}\right)=\left(\frac{X^{r}}{X^{t}+X^{r}}\right)=\left(\frac{(m-n) x^{r}}{n x^{t}+(m-n) x^{r}}\right) .
\end{aligned}
$$

We now explore equilibrium effort levels in this internal conflict. At the level of the individual, the expected cost of the ith member of town is 


$$
\begin{aligned}
c_{i}^{t}= & p^{t}\left((n-1) x^{t}+x_{i}^{t},(m-n) x^{r}\right)\left(\frac{g}{m}\right) \\
& +\left(1-p^{t}\left((n-1) x^{t}+x_{i}^{t},(m-n) x^{r}\right)\right) \\
& \times\left(\frac{g}{n}\right)+x_{i}^{t}
\end{aligned}
$$

and the corresponding expected costs to the jth member of the rural group is

$$
\begin{aligned}
c_{j}^{r}= & p^{r}\left(n x^{t},(m-n-1) x^{r}+x_{j}^{r}\right)(0) \\
& +\left(1-p^{r}\left(n x^{t},(m-n-1) x^{r}+x_{j}^{r}\right)\right) \\
& \times\left(\frac{g}{m}\right)+x_{j}^{r} .
\end{aligned}
$$

Individuals are identical, risk neutral, and select effort levels to minimize their corresponding objective functions. The first order conditions provide reaction functions for the individuals of each competing group, by which we solve for two equilibria. First, to establish a baseline, we solve a within-group cooperative equilibrium that represents an individual's contribution to the best response of their group to the actions of the other group, which is akin to members cooperating-voluntarily or through the coercion of a benevolent planner-to achieve the group's best response. Next, we solve a noncooperative Nash equilibrium that represents an individual's self-interested contribution to the group, which allows individuals to free-ride on their fellow member contributions. The two solutions indicate the role of free-riding in the conflict, which is later tested in the lab.

\section{A. Cooperative}

The cooperative individual reaction functions are calculated from Equations (2) and (3) by determining the best response by the representative member of a cooperative group taking the actions of the opposing group members as given. That is, the town members act as a singleton and choose $X t$ to minimize nct $i$ given the effort level of the rural group. Likewise, the rural group chooses $X r$ to minimize $(m-n) c r i$ given the effort level of the town. Because the members are identical, the total effort is divided symmetrically by each group. Therefore, the cooperative reaction function of a town's member, given a positive effort no greater than the cost of the cleanup is

$$
x^{t}\left(x^{r}\right)=\sqrt{\frac{g(m-n)^{2} x^{r}}{m n^{2}}}-\frac{(m-n)}{n} x^{r}
$$

and the cooperative reaction function of a rural group member, given a positive effort no greater than the cost of the cleanup is

$$
x^{r}\left(x^{t}\right)=\sqrt{\frac{g n x^{t}}{m(m-n)}}-\frac{n}{(m-n)} x^{t} .
$$


Solving for the equilibrium provides the expected expenditure of each individual in the

FIGURE 1 Cooperative Individual Reaction Functions

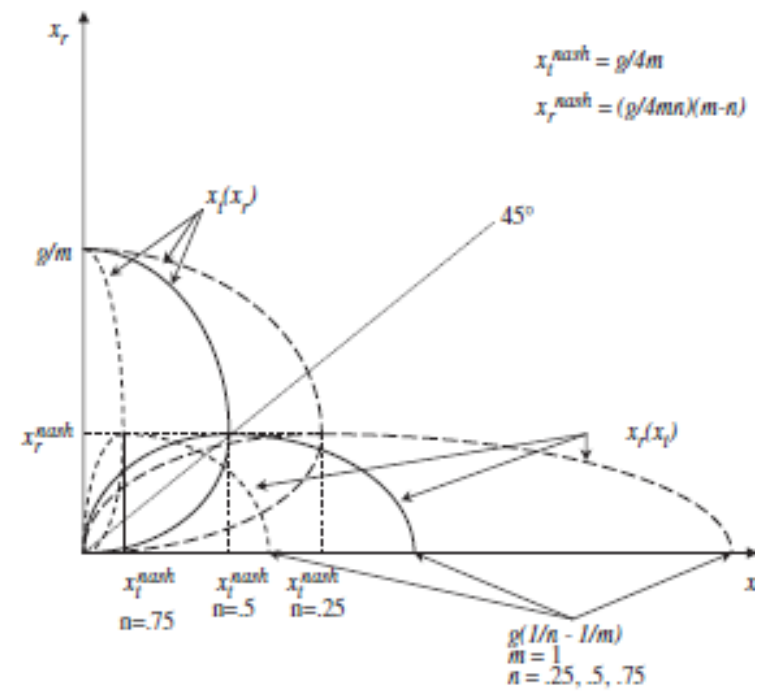

conflict when group members are cooperating (voluntarily or not) to act on behalf of their group. With each individual symmetrically and simultaneously minimizing their group's expected costs with effort levels, cleanup costs, and relative populations being common knowledge, we have the following cooperative equilibrium:

$$
\left(x^{t^{c}}, x^{r^{c}}\right)=\left[\frac{g(m-n)}{4 m n}, \frac{g}{4 m}\right] .
$$

Figure 1 illustrates the individual reaction functions and the corresponding cooperative equilibria, for given levels of $n$ relative to $m$. The population of the county is normalized to unity such that relative populations are described solely by $n$. Equilibria are characterized by the intersection of the reaction functions at each level of $n$ (the specific values of $n$ displayed are arbitrarily chosen at $0.25,0.5$, and 0.75 ).

\section{B. Noncooperative}

The noncooperative individual reaction functions are calculated from Equations (2) and (3) by determining the best response of an individual group member taking the actions of other members in her group and all members in the opposing group as given. Again, individuals are symmetric so group members will behave the same. The noncooperative reaction function of the town's representative member and the rural group's representative member, given a positive effort no greater than the cost of the cleanup, is:

(7)

$$
x^{t}\left(x^{r}\right)=\frac{(m-n)}{n}\left(\sqrt{\frac{g x^{r}}{m n}}-x^{r}\right)
$$


(8)

$$
x^{r}\left(x^{t}\right)=\frac{\sqrt{g m n x^{t}}}{m(m-n)}-\frac{n}{(m-n)} x^{t} .
$$

Solving for the noncooperative Nash equilibrium provides the expected expenditure of each individual without the presence of voluntary or coerced cooperation. With each individual simultaneously minimizing their own expected costs with effort levels, cleanup costs, and relative populations being common knowledge, we have the following noncooperative Nash equilibrium:

$$
\left(x_{i}^{x^{\text {nash }}}, x_{j}^{\text {naxh }}\right)=\left[\frac{g(m-n)^{2}}{m^{3} n}, \frac{g n}{m^{3}}\right] .
$$

Figure 2 depicts the noncooperative reaction functions and the individual Nash equilibria, for given levels of $n$ relative to $m$. As in Figure 1, the population of the county is normalized to unity such that relative populations are described solely by $n$, and equilibria for specific values of $n$ are provided. Theory provides hypotheses on how the relative size of the internal group affects effort in internal conflicts. For the cooperative case, Figure 3 depicts relationship between effort levels and the relative size of the internal group respective to the overall group size. As illustrated, effort by an internal group member is

FIGURE 2 Noncooperative Individual Reaction Functions

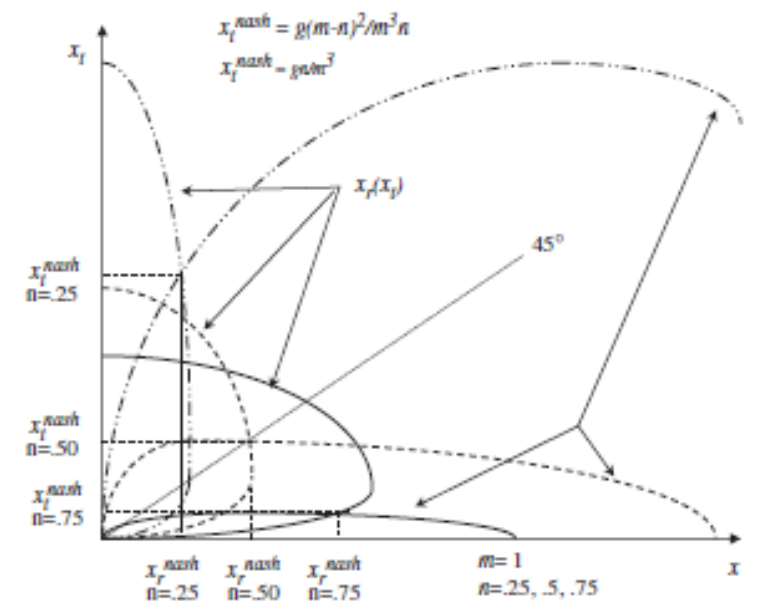


FIGURE 3 Cooperative Individual Effort Levels and Relative Group Size

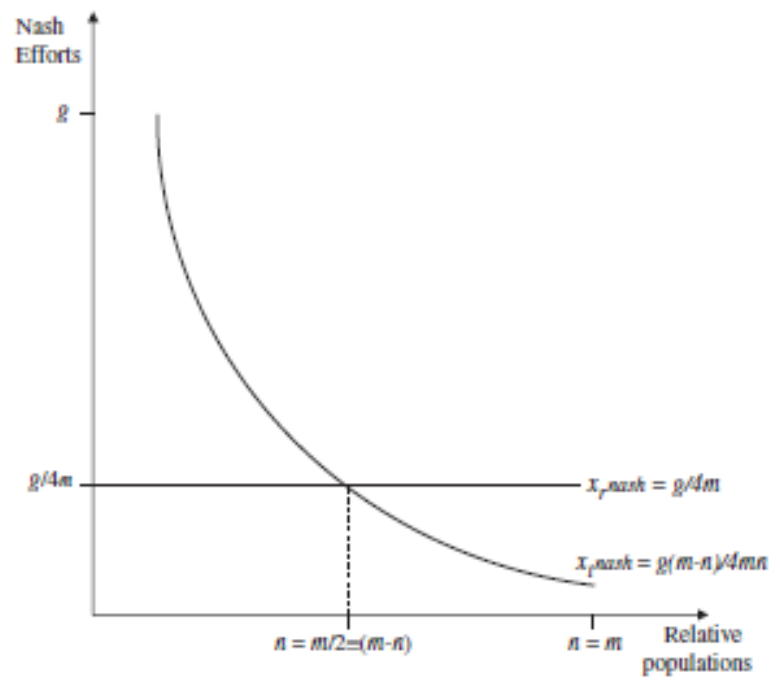

negatively related to the relative size of the internal group,10 and the effort by an external member is invariant to the relative size of the internal group. Thus we have two cooperative research hypotheses:

- Cooperative Internal Hypothesis: Individual effort by internal group (town) members declines with relative increases in the internal group size.

- Cooperative External Hypothesis: Individual effort of those outside the internal group (rural) is invariant to relative increases in the internal group size.

Turning to the noncooperative case, Figure 4 illustrates the relationship between effort levels and the relative size of the internal group respective to the overall group size. As in the cooperative case, effort by an internal group member remains negatively related to the relative size of the internal group,11 though the noncooperative Nash equilibrium predicts lower absolute effort

FIGURE 4 Noncooperative Individual Effort Levels and Relative Group Size

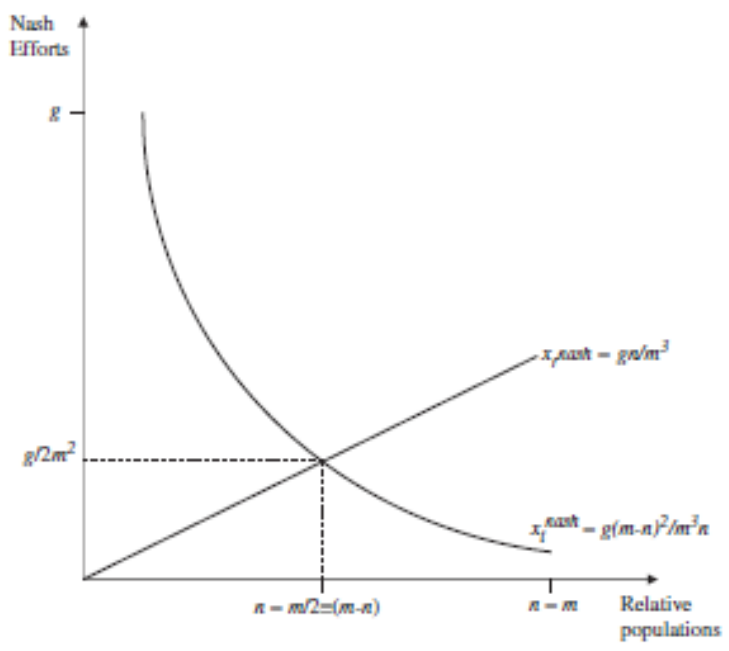


levels across the board due to the presence of free-riding. Unlike the cooperative case, effort by an external member is positively related to the relative size of the internal group. Thus we have the following two noncooperative research hypotheses:

- Noncooperative Internal Hypothesis: Individual effort by internal group (town) members declines with relative increases in the internal group size.

- Noncooperative External Hypothesis: Individual effort of those outside the internal group (rural) increases with relative increases in the relative size of the internal group size.

Figure 5 illustrates how relative group size affects total effort. In both cooperative and noncooperative cases, total effort is inversely related to the relative size of the internal group. Further, the presence of within-group strategic behavior in the noncooperative equilibrium causes total effort to be lower in the noncooperative case across all levels of the internal group's relative size.

\section{EXPERIMENTAL DESIGN}

Subjects were recruited from the undergraduate student body at a large public university to participate in a computerized contest game.

FIGURE 5 Total Effort Levels and Relative Group Size

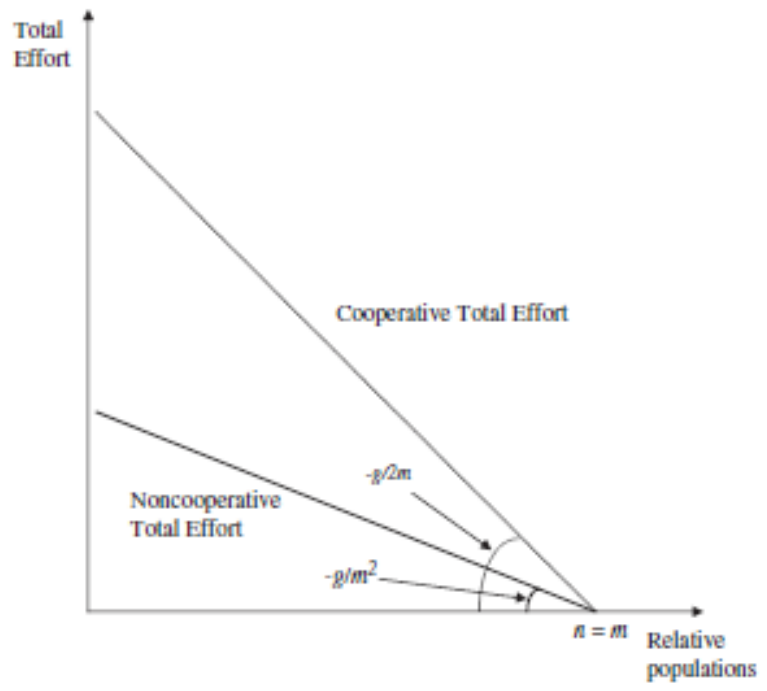

After entering the lab, participants signed a consent form acknowledging their voluntary participation while agreeing to abide by the instructions. All subjects were unfamiliar with contest games, and written protocols ensured uniformity in procedures.

\section{A. Basics}

We conducted three treatments, each consisting of two sessions. In each session, 16 subjects were randomly placed in groups of four $(m=4)$. Group members were not identified to one another, and communication was not allowed among subjects. A monitor read the experimental instructions aloud while the subjects followed along with 
individual copies. The instructions concluded with a series of questions and answers that reinforced subject understanding. After being endowed with 25 tokens, group members contended for a prize of 80 tokens $(g=80)$.

The probability function of a group winning the contest, $p t$ and $p r$ was common knowledge, and equaled the ratio of the group's effort to total effort expended by all groups. Individual member contributions to group effort, $x i$ and $x j$, were costly-one token paid for one unit of effort. Using their endowment, subjects simultaneously chose how much effort to contribute to their group's effort. Group effort, $X t$ and $X r$, the total effort contributed by members, was announced, along with the resulting probabilities for each group winning the prize. A random draw determined the winner, and individual payoffs were announced and recorded. Subsequent rounds followed with a new endowment and contest, with a total of 20 rounds. Groups were randomly reassigned after each round to minimize reputation effects. This, along with subject anonymity and no communication, minimizes the likelihood of coordination and cooperation and supports the prospects for observing individual Nash behavior. After the final round, subjects received their earnings in cash and in private, and left the lab one-by-one without any discussion.

\section{B. Treatments}

The experimental design involves three treatments, each varying by the size of the subgroup $(\varphi=n / m)$. We vary $n$, while all other parameters remain constant $(m=4, g=$ $80, p(\cdot))$, and we observe individual and group effort. In each treatment, each group of four contends with a subset of itself with the size of the subset varying across treatments; $\varphi=0.25,0.50$, or 0.75 .13

\section{Predictions and Hypotheses}

Using the cooperative equilibrium expressed in Equation (6), we identify the theoretically predicted individual effort by town members (i.e., internal group members) as: 15 tokens when $\varphi=0.25$; 5 tokens when $\varphi=0.50$; and 1.67 tokens when $\varphi=0.75$. Predicted individual effort by those outside the subgroup, or rural members, is 5 tokens in all treatments. Using the noncooperative Nash equilibrium expressed in Equation (9), we identify the theoretically predicted individual effort by town members (i.e., internal group members) as: 11.25 tokens when $\varphi=0.25 ; 2.5$ tokens when $\varphi=0.50$; and 0.417 tokens when $\varphi=0.75$. Predicted individual effort by rural members is: 1.25 tokens when $\varphi=0.25 ; 2.5$ tokens when $\varphi=0.50$; and 3.75 tokens when $\varphi=0.75$. Note the specific predictions correspond to the previously presented research hypotheses.

\section{RESULTS}

Table 1 provides the mean individual effort levels for town and rural group members in each treatment, along with a summary of the cooperative and noncooperative predictions given the experimental parameters. Table 1 also reports the predicted and observed relative effort levels, which are defined as the difference between the mean effort expended by the town and rural members (e.g., a difference of zero indicates symmetric effort). 
Results from the lab provide strong support for the noncooperative research hypotheses. As the relative size of the internal group increased, the effort expended by town members declined and the effort expended by rural members increased. Specifically, when the internal group was 25,50 , and $75 \%$ of the overall group, the internal group members (town) spent $13.86,6.18$, and 4.88 units of effort and those outside the internal group (rural) spent 3.61, 7.97, and 9.48 units. These results hold if we consider all 20 rounds or only the final five rounds of the session.

Reviewing the numbers in Table 1 more closely reveals a close correspondence between observed mean effort levels and the specific game-theoretic predictions. In treatment one $(\varphi=0.25)$, mean effort by town and rural members fell between the cooperative and noncooperative predictions, but over time, effort declined and approached the noncooperative predictions. In the final five rounds, town and rural members contributed 11.55 and 2.60 units of effort, which correspond closely to the noncooperative predictions of 11.25 and 1.25 units. With the parameters of treatment one, theory predicts asymmetric effort by town and rural members with a town member expending 10.0 more units of effort than a rural member. Actual numbers match up extremely well, with town members' mean contribution being 10.25 more than that of rural members.

Predictions in treatment two $(\varphi=0.50)$ call for symmetric effort by town and rural members -5.0 units in the cooperative solution and 2.5 units in the noncooperative solution. Mean individual effort levels observed in the lab were 6.18 and 7.97 for town and rural members, but fell to 5.60 and 6.23 units in the final five rounds. Subjects appear to be exhibiting less free-riding than predicted by theory. Results concerning relative effort levels are consistent with the symmetric prediction-the difference in mean effort by town and rural members is 1.79 over all rounds, and this difference falls to 0.62 in the final five rounds.

Observed effort levels in treatment three $(\varphi=0.75)$ are consistently above the cooperative (and noncooperative) predictions, even in the latter rounds. Actual individual effort levels for town and rural members were 4.88 and 9.48 units across all rounds, consistently greater than

TABLE 1 Predicted and Observed Individual Effort Levels by Group

\begin{tabular}{|c|c|c|c|c|c|c|c|c|}
\hline \multirow[b]{2}{*}{ Treatment } & \multicolumn{2}{|c|}{$\begin{array}{c}\text { Cooperative } \\
\text { Predicted Effort }\end{array}$} & \multicolumn{2}{|c|}{$\begin{array}{l}\text { Noncooperative } \\
\text { Predicted Effort }\end{array}$} & \multicolumn{2}{|c|}{$\begin{array}{l}\text { Observed Effort } \\
\text { (All Rounds) }\end{array}$} & \multicolumn{2}{|c|}{$\begin{array}{c}\text { Observed Effort } \\
\text { (Last } 5 \text { Rounds) }\end{array}$} \\
\hline & Town & Rural & Town & Rural & Town & Rural & Town & Rural \\
\hline \multicolumn{9}{|c|}{$\overline{\text { Absolute effort }}$} \\
\hline$\phi=0.25$ & 15.0 & 5.0 & 11.25 & 1.25 & 13.86 & 3.61 & 11.55 & 2.60 \\
\hline$\phi=0.50$ & 5.0 & 5.0 & 2.5 & 2.5 & 6.18 & 7.97 & 5.60 & 6.23 \\
\hline$\phi=0.75$ & 1.67 & 5.0 & 0.42 & 3.75 & 4.88 & 9.48 & 4.20 & 9.55 \\
\hline Treatment & \multicolumn{2}{|c|}{ Diff(Town - Rural) } & \multicolumn{2}{|c|}{ Diff(Town - Rural) } & \multicolumn{2}{|c|}{ Diff(Town - Rural) } & \multicolumn{2}{|c|}{ Diff(Town - Rural) } \\
\hline \multicolumn{9}{|c|}{ Relative effort } \\
\hline $\begin{array}{l}\phi=0.25 \\
\phi=0.50 \\
\phi=0.75\end{array}$ & & & & & & & & \\
\hline
\end{tabular}

the cooperative predictions of 1.67 and 5.0 units and the noncooperative predictions of 0.42 and 3.75 units. Though effort being above predicted levels is common is the 
experimental literature (Onculer and Croson 2005), we suspect the inflated effort levels observed in treatment three is largely due to boundary effects (e.g., Andreoni 1995; Chan et al. 1994). Thus, relative effort levels may be more instructive.14 We expect, according to theory, a town member will contribute 3.33 fewer units of effort than a rural member. We observe that town members contributed 4.60 less.

We turn to a conditional analysis of individual effort levels to confirm these initial impressions. Table 2 reports the results from the following empirical model:

$$
E_{i t}=\alpha_{i}+\theta_{i}+\omega_{i}+\psi_{t}+u_{i}+\varepsilon_{i t},
$$

where the dependent variable, $E i$, denotes the ith subject's effort level toward the conflict in period $t, \theta i$ is a vector of binary variables signifying the size of the internal group of subject i's conflict ( $\varphi=0.50$ or $0.75 ; \varphi=0.25$ omitted); $\omega i$ is a vector of interaction variables that captures the relative effect of internal group size on internal group members, $\psi t$ is a set of $T-1$ dummies that capture potential nonlinear period effects; ui are random effects which control for unobservable individual characteristics; $\alpha$ is the constant term; and $\varepsilon i t$ is the contemporaneous additive error term.

Table 2 reports the results from three models: a pooled model using the full model described in Equation (10), and two reduced models using stratified data according to group membership (town and rural). The conditional estimates confirm our initial impressions that the experimental investigation provides strong support for the noncooperative research hypotheses. From the town model, results indicate that the effort expended by internal group members is negatively related to the size of the

TABLE 2 Results from Panel Estimation of Treatment Effects

\begin{tabular}{lccc} 
& \multicolumn{3}{c}{ Group Membership } \\
\cline { 2 - 4 } & Town & Rural & Pooled \\
\hline Intercept & 15.84 & 5.40 & 5.50 \\
& $(0.000)$ & $(0.000)$ & $(0.000)$ \\
Relative group size & & & \\
$\phi=0.50$ & -7.68 & 4.36 & 4.36 \\
& $(0.027)$ & $(0.030)$ & $(0.060)$ \\
$\phi=0.75$ & -8.98 & 5.86 & 5.86 \\
& $(0.006)$ & $(0.021)$ & $(0.045)$ \\
Group membership & & & \\
$*$ Group size & & & 10.25 \\
Group B * $\phi=0.25$ & & & $(0.000)$ \\
Group B * $\phi=0.50$ & & & -1.79 \\
& & & $(0.481)$ \\
Group B * $\phi=0.75$ & & & -4.60 \\
& & & $(0.116)$ \\
$\chi^{2}$ & 33.69 & 66.22 & 70.71 \\
$(p$-value $)$ & $(0.0391)$ & $(0.0000)$ & $(0.0000)$ \\
$N$ & 480 & 480 & 960 \\
\hline
\end{tabular}

Notes: Dependent variable is individual effort, panel estimates with individual and period effects.

Figures beneath the coefficient estimates are p-values. 
internal group, which is consistent with both the cooperative and noncooperative internal hypotheses. Estimated coefficients indicate that effort by an internal group member decreases 7.68 units as the relative size of the internal group increases from 25 to $50 \%(p=0.027)$, and decreases 8.98 units as the relative size increases from 25 to $75 \%(p=0.006)$. These estimated treatment effects correspond well to the noncooperative game-theoretic predictions of 9.75 and 10.83 units.

Results from the rural model find that the effort levels of those outside the internal group are positively related to the relative size of the internal group, which is consistent with the noncooperative external hypothesis and inconsistent with the cooperative external member hypothesis. Estimates suggest that effort by those outside the internal group increases 4.36 units as the relative size of the internal group increases from 25 to $50 \%$ $(p=0.030)$, and increases 5.86 units as the relative size increases from 25 to $75 \%(p=$ 0.021 ). The estimated treatment effects are larger than predicted (1.25 and 2.5 units), and we suspect this finding is related to observed effort being inflated by a boundary effect. Results from the pooled model suggest this may be the case.

As illustrated in Table 2, the conditional estimates from the pooled model show the game-theoretic predictions are extremely accurate in describing relative behavior between competing members. The coefficients associated with the interaction vector reveal the estimated difference in effort between town and rural members conditioned on treatment effects and unobserved subject and period effects, and these differences closely match predicted behavior across all treatments. In treatment two $(\varphi=0.50)$, estimates indicate town members contributed 10.25 more units of effort than rural members $(p=0.000)$, which matches the prediction of 10 units. Also consistent with theory, in treatment three $(\varphi=0.75)$, estimates find statistically equivalent, i.e., symmetric, effort by town and rural members $(p=0.459)$. And while marginal in significance, estimates concerning treatment four $(\varphi=0.75)$ indicate town members contributed 4.60 fewer units of effort than rural members $(p=0.116)$, which corresponds well to the predicted 3.33 units.

\section{CONCLUSIONS}

Conflicts often arise between two interdependent groups, in which one group competes with a subset of itself (e.g., a conflict between a town and county over environmental cleanup costs). This paper extends the literature on collective rent-seeking to consider the possibility of this type of conflict. Theory suggests that rent dissipation decreases as the relative size of the internal group increases, and that members of the internal group respond differently to the presence of an internal conflict than those outside the internal group. The Nash equilibrium effort level expended by members of the subgroup is inversely related to the relative size of the subgroup, while the equilibrium effort expended by those outside the subgroup depends on the presence of within-group cooperation. If members cooperate on behalf of the group, effort by those outside the internal group is unaffected by the relative size of the internal group. Without cooperation (i.e., free-riding), effort by members outside the internal group is positively related to the size of the internal group increases. 
Exploring the theoretical predictions in the lab, we find the Nash equilibrium concept is a strong predictor of observed behavior in a setting of internal conflicts. Experimental results support the general hypotheses arising from theory, particularly the noncooperative Nash solutions. As the relative size of the internal group increased, members of the internal group decreased contributions of effort and members outside the internal group increased effort. 


\section{REFERENCES}

Andreoni, J. "Cooperation in Public-Goods Experiments: Kindness or Confusion?" American Economic Review, 85, 1995, 891-904.

Baik, K. H. "Effort Levels in Contests: The Public-good Prize Case." Economics Letters, 41, 1993, 363-67.

---. "Winner-help-loser Group Formation in Rentseeking Contests." Economics and Politics, 6, 1994, 147-62.

Baik, K. H., and S. Lee. "Collective Rent Seeking with Endogenous Group Sizes." European Journal of Political Economy, 13, 1997, 121-30.

---. "Strategic Groups and Rent Dissipation." Economic Inquiry, 39, 2001, 672-84. Blackwell, C., and M. McKee. "Only for My Own Neighborhood?: Preferences and Voluntary Provision of Local and Global Public Goods." Journal of Economic Behavior and Organization, 52, 2003, 115-31.

Chan, K., R. Godby, S. Mestelman, and R. Andrew Muller. "Boundary Effects and Voluntary Contributions to Public Goods." McMaster University, Department of Economics, Working Paper 94-03 1994.

Cherry, T. L., S. Kroll, and J. F. Shogren. "The Impact of Endowment Heterogeneity and Origin on Public Good Contributions: Evidence from the Lab." Journal of Economic Behavior and Organization, 57, 2005, 357-65.

Dixit, A. "Strategic Behavior in Contests." American Economic Review, 77, 1987, 89198.

Esteban, J., and D. Ray. "Social Decision Rules Are Not Immune to Conflict." Economics of Governance, 2, 2001, 59-67.

Fischbacher, U., "z-Tree: Zurich Toolbox for Ready-made Economic Experiments." Experimental Economics, 10, 2007, 171-78.

Garfinkel, M. R., and S. Skaperdas. "Economics of Conflict: An Overview," in Handbook of Defense Economics: Defense in a Globalized World, Vol. 2, Chapter 4, edited by T. Sandler and K. Hartley. Amsterdam: North Holland, 2007.

Katz, E., S. Nitzan, and J. Rosenberg. "Rent-seeking for Pure Public Goods." Public Choice, 65, 1990, 49-60.

Konrad, K. A. "Strategy in Contests: An Introduction." WZB Working Paper SP II 2007 01, 2007. 
Ledyard, J. O. "Public Goods: A Survey of Experimental Research," in Handbook of Experimental Economics, edited by J. H. Kagel and A. E. Roth. Princeton, NJ: Princeton University Press 1995, 111-94.

Lee, S. "Inter-group Competition for a Pure Private Rent." Quarterly Review of Economics and Finance, 33, 1993, 261-66.

---. "Endogeneous Sharing Rules in Collective-group Rent-seeking." Public Choice, 85, 1995, 31-44.

Nitzan, S. "Collective Rent Dissipation." The Economic Journal, 101, 1991, 1522-34.

Onucler, A., and R. Croson. "Rent-seeking for a Risky Rent: A Model of Experimental Investigation." Journal of Theoretical Politics, 17, 2005, 403-29.

Riaz, K., J. F. Shogren, and S. R. Johnson. "A General Model of Rent-seeking for Public Goods." Public Choice, 82, 1995, 243-59.

Tullock, G. "The Welfare Costs of Tariffs, Monopolies, and Theft." Economic Inquiry, 5, 1967, 224-32.

---. "Efficient Rent Seeking," in Toward a Theory of the Rent-Seeking Society, edited by G. Tullock, J. M. Buchanan, and R. D. Tollison. College Station: Texas A\&M University Press, 1980.

Ursprung, H. W. "Public Goods, Rent Dissipation and Candidate Competition." 